\title{
Bone remodeling markers: so easy to measure, so difficult to interpret
}

\author{
Ego Seeman ${ }^{1}$, Tuan V. Nguyen ${ }^{2,3,4}$
}

${ }^{1}$ Department of Medicine and Endocrinology, Austin Health, University of Melbourne, Melbourne, Australia

${ }^{2}$ Osteoporosis and Bone Biology Division, Garvan Institute of Medical Research, Sydney, Australia

${ }^{3}$ School of Public Health and Community Medicine, University of New South Wales (UNSW), Sydney, Australia

${ }^{4}$ Center for Health Technologies, University of Technology, Sydney, Australia

Corresponding author:

Ego Seeman

egos@unimelb.edu.au

Tel: +61394965640

Fax: +61394962980

Conflicts of interest: Ego Seeman and Tuan Nguyen declare that they have no conflict of interest. 


\section{Dear Editor,}

Naylor et al. report that the degree of suppression of bone remodeling markers in response to risedronate is less than with alendronate or ibandronate (1). This observation, and the lesser increase in spine bone mineral density (BMD) in the risedronate group reported previously (2), imply that preservation of structure and fracture risk reduction may be less with risedronate than with the other bisphosphonates.

Risedronate is a more potent inhibitor of farnesyl pyrophosphate synthase than alendronate or ibandronate (3-5). Risedronate also has a lower binding affinity for mineral so that this drug is likely to be more widely distributed throughout cortical matrix volume (6-9). Risedronate should therefore suppress intracortical remodeling more than alendronate or ibandronate. In animal experiments, where factors influencing remodeling independent of the treatment can be better controlled, risedronate suppresses remodeling sooner than, and to a similar degree as, alendronate $(10-12)$.

The discrepant observations in human subjects and in studies in animals and pharmacokinetics may be partly the result of issues in the execution of clinical studies and data analyses. For example, the median baseline remodeling was lower in the risedronate group. Even if not 'statistically' significant, expressing change as a percent of baseline may produce a bias such that the alendronate and ibandronate groups with higher baseline values tend to have a greater improvement in a repeat measurement even in the absence of any treatment effect. This regression to the mean of the repeat measurements may have accounted for the purported lesser reduction in remodeling markers in the risedronate group. Analysis of covariance, which takes baseline remodeling marker levels into account, does not appear to have been done.

Another challenge is that remodeling markers are not normally distributed. The authors realized this and did log transform the data, but whether the log-transformed data, expressed as mean \pm standard error of the mean (SEM), were used to compare the reduction in markers in response to treatment is not clear. Presenting the SEMs in figure 1 obscures large overlap of individual values in the three groups that can be seen from the wide $95 \%$ confidence intervals around the means in table 2. Indeed, while comparison of the decrease in remodeling markers relative to baseline within a group was done, between group statistical comparisons of the decreases in remodeling markers with each drug appear to have been done at separate time points increasing the likelihood of a type II error rather than systematically testing between group differences in an analysis of covariance model.

The authors used the least significant change (LSC) to determine whether a change within an individual exceeded random variation induced by measurement error and so identified a responder. However, the LSC approach only controls for a type I error (i.e., false positive), not a type II error (i.e., sensitivity). Thus, when a measured change is the same as the LSC, only 50\% of real changes are detected (13).

Despite "poorer" compliance in 68 subjects, it seems all 172 subjects were included in the analysis of the responses of bone markers to each drug. If so, how can responses to the treatments be evaluated, or compared if compliance differed by group. The same applies to drop outs; by 2 years, data were available in 92 subjects. Figure 1 drawn using subjects with good compliance throughout the 2 years would be of interest. Moreover, variances differ from marker to marker so comparisons within a group of the decrease in a 'resorption' marker with another 'resorption' 
marker, or with a 'formation' marker using a percentage scale may be misleading. For example, a $4 \%$ difference in height is not less than a $10 \%$ difference in weight - each is 1 standardized deviation of their respective means.

Remodeling markers are referred as 'resorption' and 'formation' markers under the assumption that these are surrogates of the respective cellular events. This jargon is used widely, if not universally, without specifying whether the terms refer to the volumes of bone resorbed and formed by the BMU, the numbers of BMUs remodeling the skeleton, both, or include the cellular activity of modeling. Remodeling markers cannot distinguish between these alternatives and cannot identify whether the cellular activity occurs upon the periosteal or endosteal (intracortical, endocortical or trabecular) envelopes.

The justification for the use of this terminology is partly the result of correlations of around 0.40.5 between resorption and formation markers and the respective surface extent of resorption and formation using histomorphometry, or respective kinetic measures derived using isotopic methods $(14,15)$. These weak correlations indicate that little of the variance in these referents is explained by the markers. Even if the correlations were high, these associations do not justify the use of this terminology because the surface extent of resorption and formation in a biopsy, or turnover rates determined using isotopic methods, reflect remodeling rate, not the net volumes of bone resorbed from the skeleton or deposited upon it, and so the terms do not capture the changes in bone microstructure that result when remodeling is suppressed by antiresorptive therapy.

During the first 3 months of antiresorptive therapy, the reduction in the concentration of a 'resorption' marker in a blood sample reflects the rapid reduction in the number and depth of BMUs excavating bone as osteoclasts imbibe bisphosphonate-laden matrix around the time of blood sampling. As the formation phase of a BMU is delayed by about 7 days (the reversal phase) and proceeds during 3 months $(16,17)$, more slowly than the 3 weeks of the resorption phase, the lesser reduction in the concentration of a 'formation' marker (relative to its baseline) in the same blood sample is the result of bone formation by the many more BMUs excavating bone before treatment. Thus, assessing differences in compliance or effectiveness of drugs using P1NP is inappropriate at early time points when steady state remodeling is acutely perturbed.

Comparing the degree of remodeling suppression produced by drugs using remodeling markers requires that steady state remodeling be restored. This occurs when therapy has been administered at around 6-12 months or later. However, if there has been attrition of subjects or poor compliance, comparisons within or between groups become problematic because randomization may be violated and factors other than the drugs influencing remodeling may differ in the three groups.

Finding a lesser reduction in 'formation' markers than 'resorption' markers, or a larger surface extent of forming than resorbing surfaces using histomorphometry can be misinterpreted to mean that a drug has a 'dual action'; inhibiting 'resorption' and allowing 'formation' to continue. Deriving a BMU balance by comparing 'resorption' and 'formation' markers is also problematic given that at no time, whether early or late in treatment, are concentrations of 'resorption' or 'formation' markers in a blood sample arising from the same BMU $(18,19)$.

Using bone remodeling markers to interpret bone remodeling at the cellular BMU level or endosteal surface level in health, disease, aging and drug therapy is fraught with challenges, particularly when the markers are referred to as 'resorption' and 'formation' markers, terminology implying the markers are accurate surrogates of these cellular events. This terminology is best 
avoided given that the terms may refer to cellular events of resorption and formation by the BMU, the surface extents of resorption and formation, or resorptive or formative modeling. The nonnormal distribution of markers and their differing variances complicate analyses calling for a need to design studies that match groups by distribution of baseline remodeling, that ensure compliance and retention of subjects, and avoid using percentages, a deceptively simple scale. There are some things statistics cannot 'adjust for'.

\section{References}

1. Naylor KE, Jacques RM, Paggiosi1 M, Gossiel F, Peel NFA, McCloskey EV, Walsh JS, Eastell R. (2015) Response of bone turnover markers to three oral bisphosphonate therapies in postmenopausal osteoporosis: the TRIO study. Osteoporos Int DOI 10.1007/s00198-0153145-7

2. Paggiosi MA, Peel N, McCloskey E, Walsh JS, Eastell R (2014). Comparison of the effects of three oral bisphosphonate therapies on the peripheral skeleton in postmenopausal osteoporosis: the TRIO study. Osteoporos Int 25:2729-2741

3. Russell RG (2006) Bisphosphonates: from bench to bedside. Ann NYAcad Sci 1068:367-401

4. Dunford JE, Thompson K, Coxon FP, Luckman SP, Hahn FM, Poulter CD, et al. (2001) Structure-activity relationships for inhibition of farnesyl diphosphate synthase in vitro and inhibition of bone resorption in vivo by nitrogen-containing bisphosphonates. J Pharmacol Exp Ther 296:235-4

5. Dunford JE, Kwaasi AA, Rogers MJ, Barnett BL, Ebetino FH, Russell RG, et al. (2008) Structure-activity relationships among the nitrogen containing bisphosphonates in clinical use and other analogues: time-dependent inhibition of human farnesyl pyrophosphate synthase. J Med Chem. 51:2187-95.

6. Smith SY, Recker RR, Hannan M, Muller R, Bauss F. (20003) Intermittent intravenous administration of the bisphosphonate ibandronate prevents bone loss and maintains bone strength and quality in ovariectomized cynomolgus monkeys. Bone 32:45-55.

7. Leu CT, Luegmayr E, Freedman LP, Rodan GA, Reszka AA. (2006) Relative binding affinities of bisphosphonates for human bone and relationship to antiresorptive efficacy. Bone 38:628-36.

8. Roelofs AJ, Stewart CA, Sun S, Błazewska KM, Kashemirov BA, McKenna CE, Russell GG, Rogers MJ, Lundy MW, Ebetino FH, Coxon FP. Influence of bone affinity on the skeletal distribution of fluorescently labeled bisphosphonates in vivo. (2012) J Bone Miner Res 27: 835-47

9. Zebaze RM, Libanati C, Austin M, et al. (2014) Differing effects of denosumab and alendronate on cortical and trabecular bone. Bone 59:173-9

10. Allen MR, Turek JJ, Phipps RJ, Burr DB. (2011) Greater magnitude of turnover suppression occurs earlier after treatment initiation with risedronate than alendronate. Bone 49:128-32.

11. Fuchs RK, Phipps RJ, Burr DB. (2008) Recovery of trabecular and cortical bone turnover following discontinuation of risedronate and alendronate therapy in ovariectomized rats. $\mathbf{J}$ Bone Miner Res. 23:1689-97.

12. Allen MR, Iwata K, Phipps R, Burr DB. (2006) Alterations in canine vertebral bone turnover, microdamage accumulation, and biomechanical properties following 1-year treatment with clinical treatment doses of risedronate or alendronate. Bone 39:872-9.

13. Iglesias N, Petersen PH, Ricós C. Power function of the reference change value in relation to cut-off points, reference intervals and index of individuality. Clin Chem Lab Med. 2005;43:441-448.) 
14. Weaver CM, Peacock M, Martin BR, McCabe GP, Zhao J, Smith DL, Wastney ME. (1997) Quantification of biochemical markers of bone turnover by kinetic measures of bone formation and resorption in young healthy females. J Bone Miner Res. 12:1714-20.

15. Eriksen EF, Charles P, Melsen F, Mosekilde L, Risteli L, Risteli J. (1993) Serum markers of type I collagen formation and degradation in metabolic bone disease: correlation with bone histomorphometry. J Bone Miner Res. 8:127-32.

16. Seeman E and Martin. (2015) Combined antiresorptive and anabolic therapy: a missed opportunity.J Bone Miner Res. 30:753-64

17. Baron, R. (1977) Importance of the intermediate phase between resorption and formation in the understanding and measurement of the bone remodeling sequence. In: Bone Histomurphometry. P.J. Meunier, ed.Laboratory Armour-Montagu, Paris. Pp 179-183.

18. Eastell R, Robins SP, T. Colwell T, Assiri AMA, Riggs BL, R. G. G. Russell RGG. (1993) Evaluation of bone turnover in type I osteoporosis using biochemical markers specific for both bone formation and bone resorption. Osteoporosis Int. 3:255-60.

19. Bieglmayer C and Kudlacek S. (2009) The bone marker plot: an innovative method to assess bone turnover in women. Eur J Clin Invest. 39: 230-238 


\section{University Library}

\section{- M M N E R VA A gateway to Melbourne's research publications}

Minerva Access is the Institutional Repository of The University of Melbourne

Author/s:

Seeman, E;Nguyen, TV

Title:

Bone remodeling markers: so easy to measure, so difficult to interpret

Date:

2016-01-01

Citation:

Seeman, E. \& Nguyen, T. V. (2016). Bone remodeling markers: so easy to measure, so difficult to interpret. OSTEOPOROSIS INTERNATIONAL, 27 (1), pp.33-35. https:// doi.org/10.1007/s00198-015-3374-9.

Persistent Link:

http://hdl.handle.net/11343/283236 